\title{
COVID-19 Update: Impact on Children's Hospitals
}

Gavin Clingham, Director of Public Policy, and the AfPA Governmental Affairs Team, Alliance for Patient Access (AfPA)

The Alliance for Patient Access (allianceforpatientaccess.org), founded in 2006, is a national network of physicians dedicated to ensuring patient access to approved therapies and appropriate clinical care. AfPA accomplishes this mission by recruiting, training and mobilizing policy-minded physicians to be effective advocates for patient access. AfPA is organized as a non-profit 501(c)(4) corporation and headed by an independent board of directors. Its physician leadership is supported by policy advocacy management and public affairs consultants. In 2012, AfPA established the Institute for Patient Access (IfPA), a related 501(c) (3) non-profit corporation. In keeping with its mission to promote a better understanding of the benefits of the physician-patient relationship in the provision of quality healthcare, IfPA sponsors policy research and educational programming.

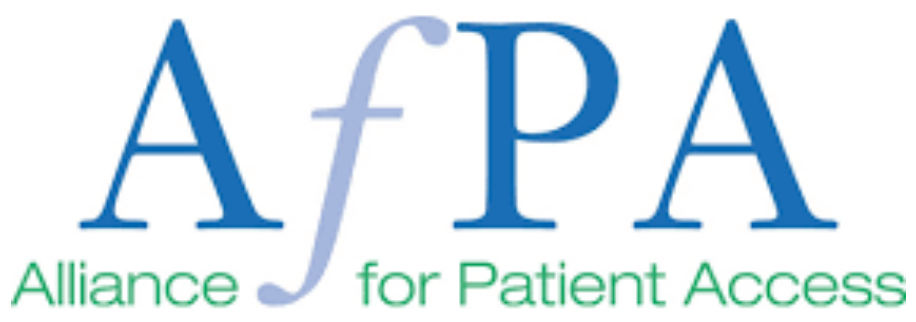

Now several months into the COVID-19 pandemic in the United States, health care experts are beginning to learn more about the virus's health implication and how it spreads. We are also learning more about the impact on the health care system.

Congress has acted several times to provide funding and equipment to health care providers, hospitals, and others impacted by this crisis. Are Children's hospitals getting their share?

\section{Impact on Health Care System}

At the very time hospitals and health care providers are most needed, these very systems are being starved of the resources required to ensure ongoing quality care. That challenge is particularly acute for Children's hospitals.

Many states have issued orders suspending elective medical procedures forcing hospitals to cancel or delay care. States have also issued stay at home orders, and many patients have been reluctant to seek treatment, concerned about being exposed to COVID-19 in a hospital setting. Further, the costs of testing and PPE have increased in all medical settings.
These factors combine in reduced revenue and increased costs to the very facilities that are most needed during this crisis.

\section{Federal Response}

Recognizing the strain on the health care system, Congress and the Department of Health and Human Services (HHS) responded by providing new large federal funding resources to augment funding that these facilities already receive.

To date, Congress appropriated more than $\$ 175$ billion for hospitals and other providers nationwide to prevent, prepare for, and respond to COVID-19. Eligible expenses include lost revenues from canceled procedures, building new structures or retrofitting existing buildings, purchasing supplies, training staff, and other COVID-19-related costs.

\section{"To date, Congress appropriated more than $\$ 175$ billion for hospitals and other providers nationwide to prevent, prepare for, and respond to COVID-19. Eligible expenses include lost revenues from canceled procedures, building new structures or retrofitting existing buildings, purchasing supplies, training staff, and other COVID-19- related costs."}

In March, Congress passed The Coronavirus Aid, Relief, and Economic Security (CARES) Act that provided an initial $\$ 100$ billion, and then Congress added $\$ 75$ billion to the fund through the next legislative package, the Paycheck Protection Program Increase Act of 2020.

HHS has been distributing this needed funding, but the formula mainly used reflects a facility's existing Medicare population as well as the number of COVID-19 patients treated. Unfortunately, this distribution does not adequately reach Children's hospitals due to their different patient and payor environment. This mismatch is despite the reality that Children's hospitals have seen the

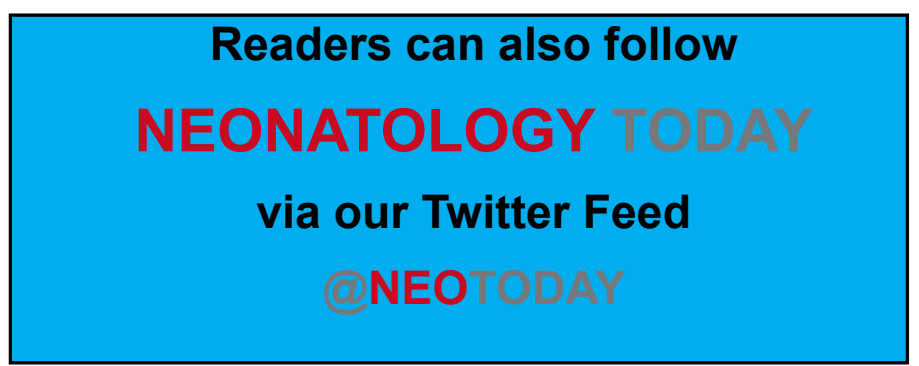


same treatment restrictions and reduction in services performed.

\section{Impact on Children's Hospitals}

Children's hospitals differ from other for-profit and non-profit hospitals in that they do not treat the Medicare population to the same extent. In fact, Medicaid is the payor for more than $50 \%$ of all patient volume.

Because Children's hospitals do not provide care for older adults, they do not benefit from remediation through Medicare, either in the form of relief from the sequester, increased reimbursement for COVID-19 patients, or access to Medicare advance payments.

According to The Children's Hospital Association, as of June: "Of the more than $\$ 190$ billion in COVID-19 relief funding allocated to health care providers to date, children's hospitals have received less than $1 \%$. This number is alarming and puts at risk the important role they serve in our communities."

https://www.childrenshospitals.org/Newsroom/Press-Releases/2020/HHS-Distribution-of-CARES-Act-to-Date-Has-Overlooked-Our-Nations-Childrens-Hospitals

"According to The Children's Hospital Association, as of June: "Of the more than $\$ 190$ billion in COVID-19 relief funding allocated to health care providers to date, children's hospitals have received less than $1 \%$. This number is alarming and puts at risk the important role they serve in our communities."

\section{Support for Children's Hospitals}

Support for providing direct funding to these facilities is growing. Industry associations such as the Children's Hospital Association are joining with individual hospitals to make their case to elected officials that support is badly needed and should be provided. This advocacy has resulted in numerous Congressional led letters to Senate and House leadership and directly to HHS Secretary Azar.

https://www.childrenshospitals.org/lssues-and-Advocacy/Medicaid/Letters-and-Testimony/2020/COVID19-funding-for-childrens-

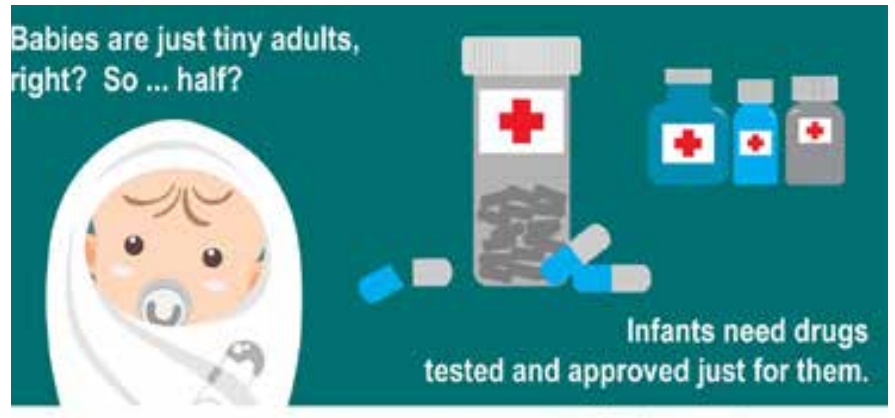

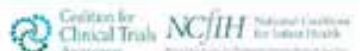
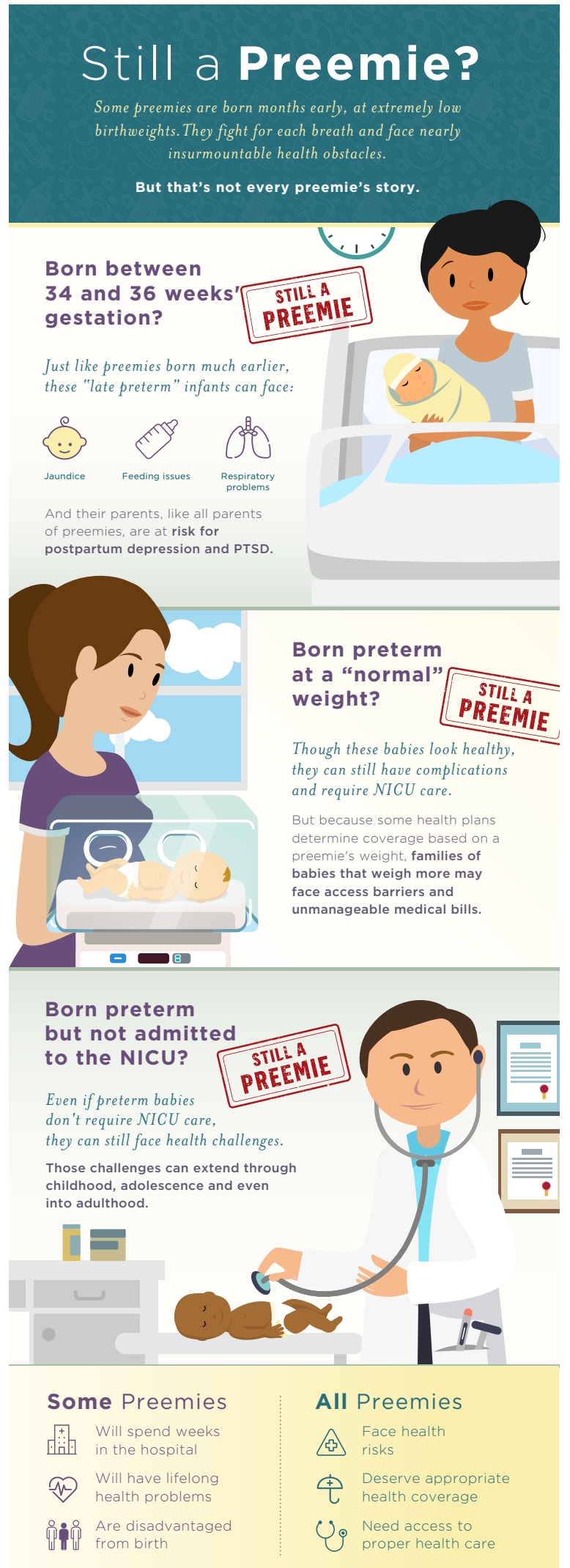

NCfIH National Coalition
for Infant Health
www.infanthealth.org 
hospitals-support-letters

The letters request that existing funding be made available to Children's hospitals, but also that new funding be provided in the next legislative package.

\section{Conclusion}

Children's hospitals play an essential role in our health care system and treat and care for our most vulnerable children. They are also the only health care sector not to receive significant federal funding support during the COVID-19 crisis.

These hospitals face the same fiscal challenges as other facilities, increased costs, limits on elective procedures, and the public's reluctance to seek care during the pandemic and need support. Congress will consider a new aid package this month and should ensure the entire health care system receives the necessary support to maintain robust care.

\section{References:}

1. https://www.childrenshospitals.org/Newsroom/Press-Releases/2020/HHS-Distribution-of-CARES-Act-to-Date-HasOverlooked-Our-Nations-Childrens-Hospitals

2. https://www.childrenshospitals.org/lssues-and-Advocacy/ Medicaid/Letters-and-Testimony/2020/COVID19-fundingfor-childrens-hospitals-support-letters

The author has not indicated any disclosures.

NT

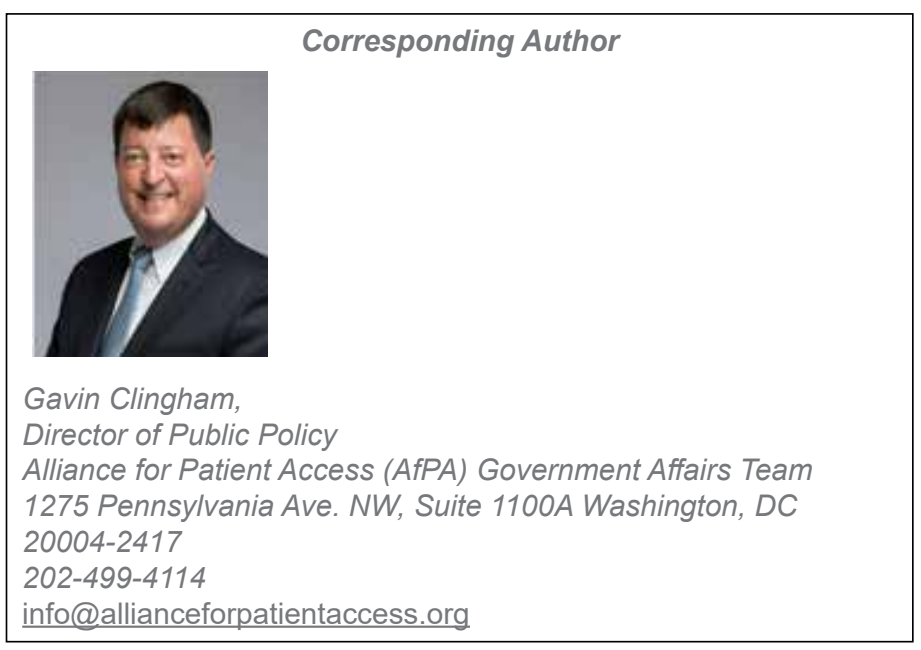

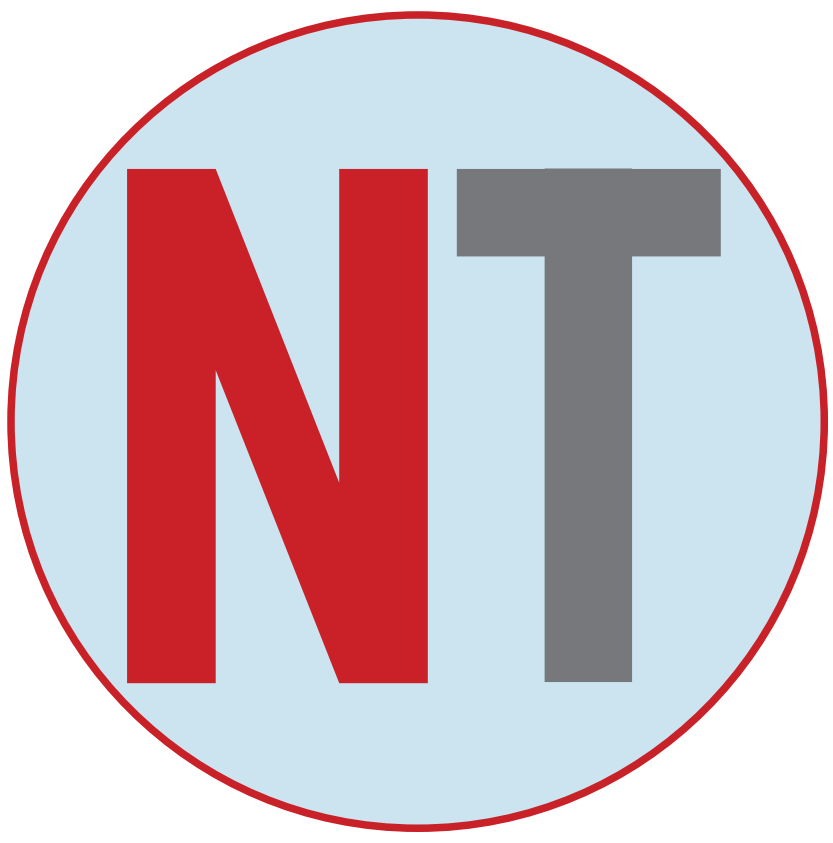

NATIONAL PERINATAL ASSOCIATION

\section{CORONAVIRUS}

COVID-19

\section{RELIABLE RESOURCES:}

- CDC: 2019 Novel Coronavirus

- The Lancet: CoviD-19 and pregnancy

- MotherToBaby: Coronaviruses

- WHO: Emerging respiratory viruses

STAY INFORMED. Perinatal

www.nationalperinatal.org

Join us in 2020 for our 41 st annual conference

\section{PERINATAL CARE in the $4^{\text {th }}$ TRIMESTER: Redefining Prenatal, Postpartum. and Neonatal Care for a New Generation}

December 2 - 4 Hyatt Regency Aurora-Denver www.nationalperinatal.org/2020 